the miner is apprehension of danger; due to difficulty of fixation. Along with this there is dazzling and blepharospasm. An " anxiety neurosis " may develop in two directions. In one the prominent symptoms are $\cdot$ disordered heart action, excessive sweating, dilated pupils and irritability and lack of concentration. In the other, the symptoms are more purely mental, and include irritability, depression, forebodings, apprehensions and disturbed sleep. It is reported by Dr. Eddison that there are two main varieties of the affection as a whole (that is of the disease known as miners' nystagmus), namely, a group beginning with nystagmus and followed by an anxiety state, and a group in which the psychoneurotic symptoms are primary. In these cases nystagmus may not be present at all times.

In some cases then " the state known as miners' nystagmus may be a psycho-neurosis arising independently of any disorder of eye movements or of vision, while in others the psycho-neurotic aspect of the disease, though secondary to nystagmus proper, has come to be the more important part of the disease." After referring to the fact that in most psycho-neuroses some special experience serves as a nucleus round which other symptoms tend to centre, the Report goes on to say :- " Through the prevalence of nystagmus the miner is provided with such a nucleus for his psychoneurotic symptoms. . . . The mechanism of the production of psycho-neurosis secondary to miners' nystagmus makes it clear why compensation should have produced so great an increase in the number of those in whom nystagmus has produced a disability to work. . . . Through the fact and prevalence of compensation nystagmus has become so familiar to the miner that it is at once seized upon as the cause of any aches, pains, or other disturbances of the normal course of his life, and provides a nucleus for psycho-neurotic troubles."

We may conclude this somewhat lengthy analysis of a most important Report by saying that as in the body of the Report defective illumination is considered to be the essential cause of miners' nystagmus, so at the end of it improvement in illumination is considered to be the preventive, not only of nystagmus itself, but, by lessening the tendency to apprehension and consequent repression, of those cases of psycho-neurosis in which nystagmus is absent.

\title{
On the value of Good Lighting in preventing Industrial Accidents, and increasing Production
}

In the address delivered before the Illuminating Engineering Society on Tuesday, February 28, Mr. Leon Gaster (Hon. Secretary of the Society) drew attention to the importance of good lighting in factories, as an essential to the health and safety of 
workers, and as a condition of efficient and rapid work: Experience had shown that there was a close connection between the prevalence of accidents and the lighting conditions, and tests indicated that improvements in lighting led to considerable advances in output, and diminution of spoiled work. Generally speaking, the cost of lighting formed only a very small proportion, usually less than one per cent. of the costs of production. Expenditure to secure proper lighting was, therefore, a good investment and should be regarded as a national asset.

Ideal requirements should enable work to proceed at night with the same ease and safety as in good daylight. The necessary conditions had been admirably summarized in the reports issued by the Home Office Departmental Committee on Lighting in Factories and Workshops. The Home Office had for a number of years taken a great interest in industrial lighting, and in this respect this country was in advance of the rest of Europe. In discussing legislative requirements, Mr. Gaster pointed out the necessity for the framing of general lighting recommendations, which could readily be carried out, and would be of great benefit both to employers and workers.

\section{OPHTHALMOLOGICAL SOCIETY OF THE UNITED KINGDOM}

The Tenth Annual Congress was held in London on May 11, 12 , and 13,1922 , and was well attended. The proceedings were conducted by the President, Mr. J. Herbert Fisher, who, at the opening session at 1 , Wimpole Street, presented the Edward Nettleship Prize to Dr. H. Moss Traquair, of Edinburgh. As the President remarked, Dr. Traquair's original work on perimetry, especially with regard to pituitary disease, is well known, and has laid a sure foundation for future investigation.

Mr. MAYOU described the various types of corneal ulceration met with as a result of ophthalmia neonatorum, and advised that no operation should be undertaken for small punctured ulcers with iris inclusion. Larger perforations, however, might require iridectomy for optical purposes; he considered that it should be done upwards rather than downwards to avoid dazzling from the coloboma. He also suggested that the incision for the iridectomy should be made at the scar in the corneal centre, as it is easier to tear away a bit of iris from the periphery than from the leucoma. Such an operation should be postponed until the child has been weaned. 